\title{
Back to the drawing board: Re-thinking the role of GLI1 in
}

\section{pancreatic carcinogenesis [version 1; peer review: 3 approved]}

\author{
Tara L. Hogenson', Matthias Lauth², Marina Pasca diMagliano3, \\ Martin E. Fernandez-Zapico (D)1
}

${ }^{1}$ Schulze Center for Novel Therapeutics, Mayo Clinic, Rochester, MN 55905, USA

2Institute of Molecular Biology and Tumor Research, Philipps University, Marburg, 35043, Germany

${ }^{3}$ Department of Surgery, University of Michigan, Ann Arbor, MI 48109-5936, USA

V1 First published: 08 Oct 2014, 3:238

https://doi.org/10.12688/f1000research.5324.1

Latest published: 23 Jun 2016, 3:238

https://doi.org/10.12688/f1000research.5324.2

\section{Abstract}

Aberrant activation of the transcription factor GLI1, a central effector of the Hedgehog $(\mathrm{HH})$ pathway, is associated with several

malignancies, including pancreatic ductal adenocarcinoma (PDAC), one of most deadly human cancers. GLI1 has been described as an oncogene in PDAC, making it a promising target for drug therapy. Surprisingly, clinical trials targeting HH/GLI1 axis in advanced PDAC were unsuccessful, leaving investigators questioning the mechanism behind these failures. Recent evidence suggests the loss of GLI1 in the later stages of PDAC may actually accelerate disease. This indicates GLI1 may play a dual role in PDAC, acting as an oncogene in the early stages of disease and a tumor-suppressor in the late stages.

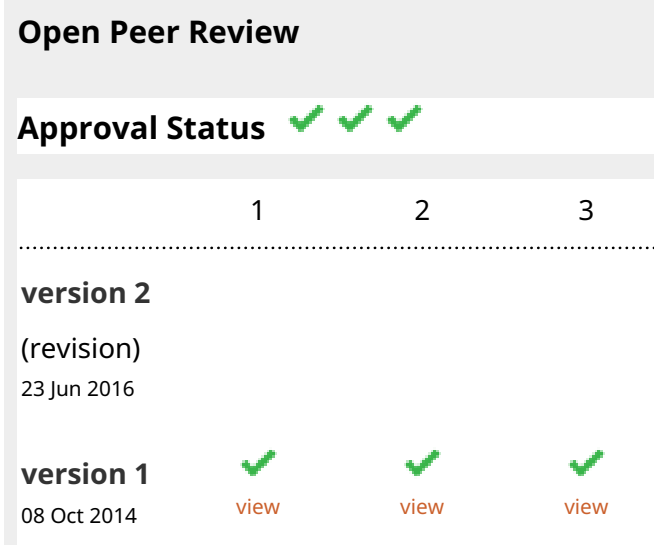

1. Alain Mauviel, Institut Curie, Orsay, France

2. Natalia Riobo, Thomas Jefferson University, Philadelphia, USA

3. Barbara Stecca, Core Research LaboratoryIstituto Toscano Tumori, Florence, Italy Any reports and responses or comments on the article can be found at the end of the article. 
Corresponding author: Martin E. Fernandez-Zapico (fernandezzapico.martin@mayo.edu)

Competing interests: No competing interests were disclosed.

Grant information: This work was supported by National Institutes of Health Grant CA136526, Division of Oncology Research (Mayo Clinic), Mayo Clinic Pancreatic SPORE P50 Grant CA102701 and Mayo Clinic Center for Cell Signaling in Gastroenterology Grant P30 DK84567 (to M.E.F.-Z.).

The funders had no role in study design, data collection and analysis, decision to publish, or preparation of the manuscript.

Copyright: (c) 2014 Hogenson TL et al. This is an open access article distributed under the terms of the Creative Commons Attribution License, which permits unrestricted use, distribution, and reproduction in any medium, provided the original work is properly cited. Data associated with the article are available under the terms of the Creative Commons Zero "No rights reserved" data waiver (CC0 1.0 Public domain dedication).

How to cite this article: Hogenson TL, Lauth M, Pasca diMagliano M and Fernandez-Zapico ME. Back to the drawing board: Rethinking the role of GLI1 in pancreatic carcinogenesis [version 1; peer review: 3 approved] F1000Research 2014, 3:238

https://doi.org/10.12688/f1000research.5324.1

First published: 08 Oct 2014, 3:238 https://doi.org/10.12688/f1000research.5324.1 


\section{Introduction}

The protein GLI1, originally isolated in 1987 due to high levels of amplification in malignant glioma (Kinzler et al., 1987), is a member of the GLI family of transcription factors. This family also includes GLI2 and GLI3. GLI1 is highly conserved from Drosophila to humans and is required for developmental response via transcriptional regulation of target genes (Dennler et al., 2007; Hui \& Angers, 2011; Javelaud et al., 2012). The GLI proteins, including GLI1, are transcriptional mediators of Hedgehog $(\mathrm{HH})$ signaling, and regulate multiple cellular processes such as cell fate determination, tissue patterning, proliferation and transformation, which give this transcription factor a significant role in carcinogenesis if deregulated (Dennler et al., 2007; Hui \& Angers, 2011; Javelaud et al., 2012). GLI1 is expressed in different human malignancies including pancreatic ductal adenocarcinoma (PDAC) (Eberl et al., 2012; Fiaschi et al., 2009; Goel et al., 2013; Hui \& Angers, 2011; Mills et al., 2013; Rajurkar et al., 2012; Thayer et al., 2003). In PDAC, GLI1 is prevalently expressed in the stroma, in response to HH ligands secreted by the epithelial cells (Yauch et al., 2008). However, lower epithelial expression of Gli1 has also been reported, possibly with non-canonical functions (Nolan-Stevaux et al., 2009).

\section{GLI1 as an oncogene in PDAC}

GLI1 plays a key role in PDAC initiation by modulating the activity of two different cellular compartments, the epithelium and stroma. Rajurkar et al. demonstrated that targeted overexpression of GLI1 in the pancreas epithelium accelerates PDAC initiation by KRAS, a small GTPase mutated in more than $90 \%$ of PDAC cases (Rajurkar et al., 2012). Through use of a mouse model with simultaneous activation of oncogenic KRAS and inhibition of GLI1 in the pancreas epithelium, this group also demonstrated that decreased GLI1 activity reduced the incidence of KRAS-driven PDAC precursor lesions (pancreatic intraepithelial neoplasias or PanINs) and PDAC. Similarly, Mills and colleagues using a mouse model for pancreasspecific oncogenic KRAS expression (KC mice) bred on a Gli1 null background $(\mathrm{GKO} / \mathrm{KC})$ defined a key role for GLI1 on PDAC initiation through the modulation of the activity of fibroblasts (Mills et al., 2013). The KC mice developed PanIN lesions with $100 \%$ penetrance and PDAC in advanced age, while the $\mathrm{GKO} / \mathrm{KC}$ mice did not develop PDAC and had increased survival rate when compared to $\mathrm{KC}$ mice. Histopathological analysis of the pancreata showed KC mice developed PanIN lesions and PDAC, while $80 \%$ of $\mathrm{GKO} / \mathrm{KC}$ had normal pancreata.

Analysis of the molecular mechanism underlying this phenomenon reveals that GLI1 both regulates different target genes and is modulated by different signaling pathways depending on the cellular compartment. For instance, GLI1 activity is mainly modulated by the canonical HH signaling in fibroblasts (Yauch et al., 2008). This cascade is activated by binding of the ligand to the receptor Patched (Ptch), resulting in activation of the G-coupled receptor, Smoothened (Smo) (Javelaud et al., 2012; Yauch et al., 2008). Once activated, Smo induces GLI1 activation and upregulation of its target genes (Hui \& Angers, 2011; McMahon et al., 2003). The $\mathrm{HH}$ ligand, Sonic Hedgehog ( $\mathrm{SHH})$, and components of the $\mathrm{HH}$ signaling pathway, including Ptch and Smo, are undetectable in the normal pancreas but overexpressed in PanINs and PDAC (Thayer et al., 2003). Inhibition of the HH pathway in PDAC cell-based xenograft models through Smo inhibition has been shown to reduce
GLI1 activity and tumor growth (Feldmann et al., 2007; Thayer et al., 2003; Yauch et al., 2008). In addition, genomic sequencing of human pancreatic cancer samples revealed widespread mutations consistent with activation of the Hedgehog signaling pathway (Jones et al., 2008). While the association between HH activity and pancreatic cancer has been described over a decade ago, there is still uncertainty as to the downstream effect of $\mathrm{HH}$ activation in this disease. Mills et al. identified the cytokine IL-6 as a HH/GLI1 target gene in pancreatic fibroblasts (Mills et al., 2013). Increased IL-6 expression in the stromal compartment induces activation of STAT3 in the neighboring cancer cells, an essential molecular event for the progression of premalignant lesions in PDAC (Figure 1).

\section{Hedgehog-independent mechanisms for GLI1 expression in PDAC}

While dysregulation of HH-GLI1 signaling has been shown to play an important role in PDAC formation, several studies have demonstrated that GLI1 expression can be activated through $\mathrm{HH}$ independent mechanisms in PDAC, particularly in the epithelial compartment (Dennler et al., 2007; Eberl et al., 2012; Goel et al., 2013; Ji et al., 2007; Nolan-Stevaux et al., 2009; Nye et al., 2014). Nolan-Stevaux et al. demonstrated that deletion of Smo receptor in pancreatic epithelium had no effect on KRAS induced tumor formation, nor on GLI1 expression in epithelial cells (Nolan-Stevaux et al., 2009). This indicates a Smo-independent mechanism for GLI1 regulation in PDAC cells downstream of KRAS. In fact, Ji et al. demonstrated that KRAS is a modulator of GLI1 activity and requires the transcription factor for PDAC growth in vitro (Ji et al., 2007). In the epithelial compartment, GLI1 is regulated in a HHindependent manner, downstream of KRAS. Accordingly, Ji et al. showed that Gli1 protein degradation is blocked in a MAPKdependent manner. Furthermore, Rajurkar et al. showed a role for GLI1 in the regulation of the NF- $\kappa \mathrm{B}$ pathway, a signaling cascade linked to PDAC development (Algul et al., 2002; Ougolkov et al., 2005; Pan et al., 2008; Wang et al., 1999), downstream of KRAS (Rajurkar et al., 2012). This group has identified the I-kappa-B kinase epsilon (IKBKE)/NF- $\mathrm{BB}$ pathway as a direct target of the GLI1 mediating KRAS-dependent pancreatic epithelial transformation in vivo (Junhao Mao, University of Massachusetts and Martin E. Fernandez-Zapico personal communication).

PDAC is characterized by a dense desmoplastic reaction associated with the primary tumor. The abundance of connective tissue is due to an increase in growth factor production in the tumor microenvironment through autocrine and paracrine oncogenic signaling pathways (Mahadevan \& Von Hoff, 2007). Oncogenic KRAS activates $\mathrm{SHH}$ production, but $\mathrm{HH}$ ligands do not activate the $\mathrm{HH}$ pathway in tumor epithelial cells in an autocrine manner (Lauth et al., 2010; Mills et al., 2013; Yauch et al., 2008). HH signaling in PDAC occurs in a paracrine fashion where $\mathrm{HH}$ signaling from PDAC cells to stromal cells has been shown to promote desmoplasia (Yauch et al., 2008). Lauth et al. demonstrated that this shift from autocrine to paracrine signaling is through activation of the RAS effector dual specificity tyrosine phosphorylated and regulated kinase 1B (DYRK1B) (Lauth et al., 2010). The authors proposed this is achieved through DYRK1B inhibition of GLI2 function and promotion of the repressor GLI3, and subsequent inhibition of GLI1, in PDAC cells. 


\section{Early Stages of PDAC}

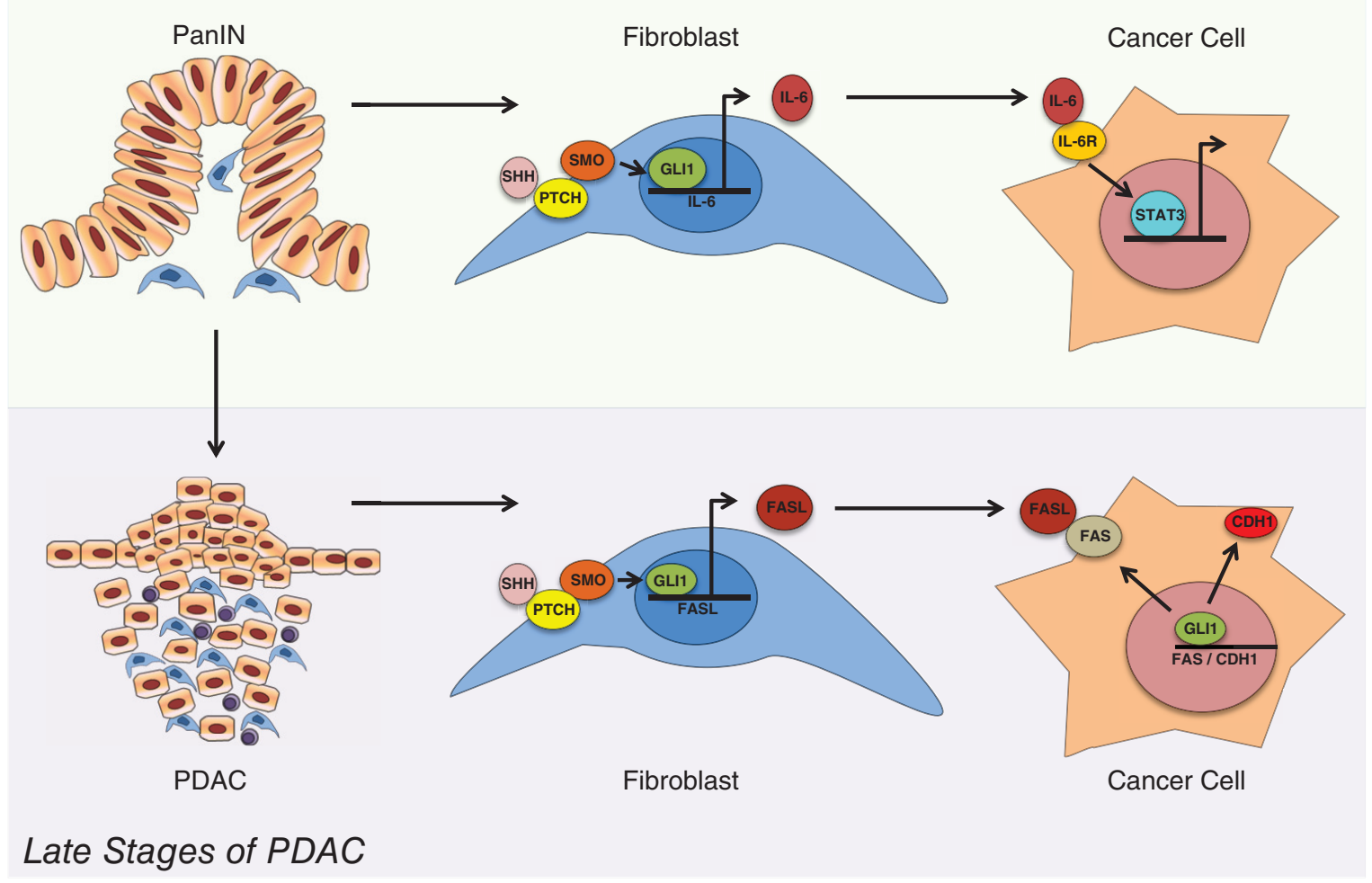

Figure 1. Working model of the dual role of GLI1 at different stages of pancreatic carcinogenesis. During the early stages of PDAC, GLI1 is activated in the fibroblasts through canonical HH signaling. GLI1 promotes expression of the cytokine IL-6, which stimulates expression of STAT3 in neighboring cancer cells, promoting the progression of PanIN lesions to PDAC. In the later stages of PDAC, GLI1 binds the FASL promoter and regulates the expression of this ligand in the fibroblast, leading to higher levels of apoptosis in these tumors. In addition, in cancer cells, GLI1 induces the expression of FAS and CDH1 expression, leading to a tumor protective effect.

TGF $\beta$ has been shown to promote GLI1 expression in pancreatic cancer cells (Nolan-Stevaux et al., 2009). TGF $\beta$ induces the expression of GLI1 through Smad3 and LET-dependent upregulation of GLI2 independent of HH signaling (Dennler et al., 2007; Dennler et al., 2009). Nye et al. demonstrated that TGF $\beta$, in addition to controlling GLI1 expression, can also modulate its activity by promoting the formation of a transcriptional complex with the TGF $\beta$ regulated transcription factors, SMAD2 and 4, and the histone acetyltransferase, PCAF, in cancer cells to regulate TGF $\beta$-induced gene expression (Nye et al., 2014). TGF $\beta$ induced GLI2 expression, and subsequent GLI1 activation, is associated with epithelial to mesenchymal transition (EMT), tumor growth, and metastasis (Javelaud et al., 2012).

In addition to TGF $\beta$ and KRAS activation, epidermal growth factor receptor (EGFR) signaling, a cascade aberrantly activated in the majority of PDACs, has been demonstrated to play a critical role in HH/GLI1-regulated tumor-initiating pancreatic cancer cells (Eberl et al., 2012). Eberl and colleagues demonstrated EGFR and HH act together to promote cancer cell proliferation by modulating gene expression through a GLI1-dependent mechanism. This suggests HH/GLI1 signaling works synergistically through distinct novel pathways during tumor initiation and growth.
Clinical trials targeting the hedgehog/GLI1 axis in PDAC The concept that HH/GLI1 signaling might be required for PDAC growth, hence a suitable therapeutic target, has been first validated in a genetically engineered mouse model of pancreatic cancer that combines expression of oncogenic Kras with mutation of the tumor suppressor p53, the KPC mouse (Hingorani et al., 2005). Treatment of KPC mice with a Smo inhibitor in combination with gemcitabine led to a moderate but significant increase in survival (Feldmann et al., 2008; Olive et al., 2009). A preclinical study of the $\mathrm{HH}$ inhibitor, saridegib (IPI-926), co-administered with gemcitabine, produced a transient increase in vascular density, increased chemotherapy drug delivery, and improved disease stabilization in pancreatic cancer cells (Olive et al., 2009). Based on these results, phase II clinical trials were approved evaluating saridegib and an additional Hh inhibitor, vismodegib (GDC-0449), for treatment of pancreatic cancer. Surprisingly, the clinical trial for both vismodegib and saridegib showed a higher rate of progressive disease when compared to placebo (Catenacci et al., 2013). Similar findings were seen in a separate phase I trial of vismodegib in 8 patients with pancreatic cancer (LoRusso et al., 2011). Although hedgehog inhibitors have been successful for treating basal cell carcinoma and medulloblastoma, they do not appear to have the same effect in advanced pancreatic cancer. 
These disappointing results left investigators questioning the molecular mechanism responsible for these failed clinical trials. Although there is overwhelming evidence that GLI1 plays an important role in tumor initiation and progression of several kinds of malignancies, these results suggest the transcription factor may have a tumor protective role in the later stages of certain cancers. In fact, recent studies investigating GLI1 expression in PDAC have revealed GLI1 may switch from a tumor promoting to a tumor protective molecule in the later stages of PDAC.

\section{GLI1 as a tumor suppressor in PDAC}

In contrast to the current paradigm for GLI1 expression and tumor progression, one study found GLI1 expression may actually decrease cell motility in advanced PDAC (Joost et al., 2012). Joost et al. demonstrated that GLI1 regulates epithelial differentiation through transcriptional activation of the cell adhesion molecule, E-Cadherin (CDH1), in PDAC cells. Lowered expression of GLI1 in PDAC cells lead to a loss of $\mathrm{CDH} 1$ expression and promotion of EMT. The transition from epithelial to motile mesenchymal cells is thought to be a critical event for metastasis of carcinomas. Decreased expression of $\mathrm{CDH} 1$ is associated with increased metastasis and invasion, while increased expression is associated with lower tumor malignancy (Seidel et al., 2004; von Burstin et al., 2009). PDAC is strongly associated with early invasion and metastasis. Loss of GLI1 was also shown to decrease expression of additional important epithelial marker genes, including Keratin 19 (KRT19) and adherens junctions components EVAl and PTPRM, leading to increased cell motility. This indicates that as PDAC progresses, lower GLI1 levels may actually prime tumor cells towards an EMT program, which would be associated with metastasis and advanced stages of the disease.

Mills et al. examined the role of GLI1 expression in the later stages of PDAC using a mouse model for advanced pancreatic cancer (Mills et al., 2014). In this study, the loss of GLI1 actually accelerated PDAC progression during the later stages of tumorigenesis. PDAC mice lacking GLI1 showed reduced survival when compared to GLI1 wild type littermates. While both cohorts of mice displayed the common features of advanced PDAC, loss of GLI1 was associated with decreased survival and increased tumor burden. Analysis of the mechanism revealed the pro-apoptotic FAS/FASL axis as a potential mediator for this phenomenon. Loss of GLI1 was associated with a significant decrease in expression of FAS/FASL, leading to lower apoptosis levels and increased tumor progression (Figure 1).

In agreement with these findings, two recent studies demonstrated that the deletion of the GLI1 inducer SHH, using a mouse model for PDAC, led to more aggressive tumors (Lee et al., 2014; Rhim et al., 2014). Interestingly, Rhim's study reported the occurrence of poorly differentiated tumors, with increased vascularity, and significantly reduced stromal content. In contrast, the Lee paper only described a modest reduction in the stromal compartment. The current paradigm for PDAC is that the tumor stroma plays an important role in promotion of neoplastic growth and progression since PDAC is typically associated with a dense desmoplastic reaction. However, the Rhim study shows that tumors with reduced stroma may display a more aggressive behavior than those with an extensive stromal compartment. This concept is further supported by a recent report demonstrating that tumor stroma restrains pancreatic cancer progression and that pharmacological $\mathrm{HH}$ pathway activation in stromal cells can actually slow down in vivo tumorigenesis (Lee et al., 2014). The complexity of these findings reflects our incomplete understanding of the precise biological role of HH/GLI1 signaling in pancreatic cancer. In fact, the level of activation of $\mathrm{HH}$ signaling might induce different biological responses during the carcinogenesis process, as commonly observed during embryonic development. In fact, manipulation of the membrane mediators of $\mathrm{HH}$ signaling to reduce $\mathrm{HH}$ signaling leads to an increase of angiogenesis with low $\mathrm{HH}$ levels, but not with complete inhibition. Intriguingly, the Rhim and Lee studies generated a low $\mathrm{HH}$ signaling environment by eliminating $\mathrm{SHH}$, but not $\mathrm{IHH}$, another $\mathrm{HH}$ ligand expressed in pancreatic cancer. Similarly, studies altering the expression of Gli1 leave intact the other mediators of HH signaling, GLI2 and GLI3 (the latter mainly an inhibitor of $\mathrm{HH}$ target genes). It remains to be seen if manipulating GLI1 levels within the epithelial tumor compartment in later stages of disease is of any therapeutic value. Based on work from Fendrich et al. on HH signaling and acinar cell differentiation, it might even be provocatively proclaimed that increasing GLI1 levels could drive terminal differentiation and thus result in lower tumorigenicity (Fendrich et al., 2008).

\section{Discussion}

These studies demonstrating GLI1 may act as a tumor suppressor in the late stage of PDAC give insight into the disappointing results of clinical trials testing $\mathrm{HH}$ inhibitors in metastatic PDAC patients. While the Olive experiments reported acute administration of IPI-926 increased survival due to decreased stromal content and increased vascularity, the $\mathrm{HH}$ inhibitor performed poorly in pancreatic cancer clinical trials in patients. One explanation for this discrepancy may be the short duration of treatment (3 weeks) in the Olive's experiments, which may have not accurately detected disease progression following $\mathrm{HH}$ inhibition. This indicates that as PDAC progresses, the initial positive effects of $\mathrm{HH}$ inhibition may be eliminated as GLI1 levels decrease. In Rhim's study, the authors discovered that SHH and GLI1 deficient tumors were more aggressive, poorly differentiated, and exhibited increased vascularity (Rhim et al., 2014). This suggests HH/GLI1 pathway inhibition may have a proangiogenic effect. Due to the increase in vascularity of the SHH deficient mice tumors, the authors investigated the effect of angiogenesis inhibition by administering anti-VEGF to tumor-bearing SHH deficient mice. This therapy led to a significant improvement in the overall survival of mice with undifferentiated tumors. Based on this response, the subset of PDAC patients with undifferentiated tumors may benefit from anti-angiogenic therapy. In summary, due to the high complexity of PDAC initiation and progression, a personalized strategy for treatment should be considered. Under this strategy, PDAC should be analyzed before treatment to determine expression of GLI1 and upstream regulators in order to better define therapeutic options.

\section{Author contributions}

T.L.H and M.E.F.-Z. developed the concept of the review and T.L.H, M.L., M.P.M. and M.E.F.-Z. wrote the manuscript. 


\section{Competing interests}

No competing interests were disclosed.

\section{Grant information}

This work was supported by National Institutes of Health Grant CA136526, Division of Oncology Research (Mayo Clinic), Mayo

Clinic Pancreatic SPORE P50 Grant CA102701 and Mayo Clinic
Center for Cell Signaling in Gastroenterology Grant P30 DK84567 (to M.E.F.-Z.).

The funders had no role in study design, data collection and analysis, decision to publish, or preparation of the manuscript.

\section{Acknowledgments}

We thank Emily Porcher and Pam Becker for secretarial assistance.
Algul H, Adler G, Schmid RM: NF-kappaB/Rel transcriptional pathway: implications in pancreatic cancer. Int J Gastrointest Cancer. 2002; 31(1-3): 71-78. PubMed Abstract | Publisher Full Text

Catenacci D, Bahary N, Sreenivasa RN, et al.: Final analysis of a phase IB/ randomized phase II study of gemcitabine $(G)$ plus placebo $(P)$ or vismodegib (V), a hedgehog (Hh) pathway inhibitor, in patients (pts) with metastatic pancreatic cancer (PC): A University of Chicago phase II consortium study. J Clin Oncol. 2013; 31(suppl; abstr 4012).

Reference Source

Dennler S, Andre J, Alexaki I, et al.: Induction of sonic hedgehog mediators by transforming growth factor-beta: Smad3-dependent activation of Gli2 and Gli expression in vitro and in vivo. Cancer Res. 2007; 67(14): 6981-6986.

PubMed Abstract | Publisher Full Text

Dennler S, Andre J, Verrecchia F, et al.: Cloning of the human GLI2 Promoter: transcriptional activation by transforming growth factor-beta via SMAD3/betacatenin cooperation. J Biol Chem. 2009; 284(46): 31523-31531.

PubMed Abstract | Publisher Full Text | Free Full Text

Eberl M, Klingler S, Mangelberger D, et al.: Hedgehog-EGFR cooperation response genes determine the oncogenic phenotype of basal cell carcinoma and tumour-initiating pancreatic cancer cells. EMBO Mol Med. 2012; 4(3): 218-233. PubMed Abstract | Publisher Full Text | Free Full Text

Feldmann G, Dhara S, Fendrich V, et al.: Blockade of hedgehog signaling inhibits pancreatic cancer invasion and metastases: a new paradigm for combination therapy in solid cancers. Cancer Res. 2007; 67(5): 2187-2196.

PubMed Abstract | Publisher Full Text | Free Full Text

Feldmann G, Habbe N, Dhara S, et al.: Hedgehog inhibition prolongs survival in a genetically engineered mouse model of pancreatic cancer. Gut. 2008; 57(10) $1420-1430$.

PubMed Abstract | Publisher Full Text | Free Full Text

Fendrich V, Esni F, Garay MV, et al:: Hedgehog signaling is required for effective regeneration of exocrine pancreas. Gastroenterology. 2008; 135(2): 621-31. PubMed Abstract | Publisher Full Text | Free Full Text

Fiaschi M, Rozell B, Bergström A, et al.: Development of mammary tumors by conditional expression of GLI1. Cancer Res. 2009; 69(11): 4810-4817.

PubMed Abstract | Publisher Full Text | Free Full Text

Goel HL, Pursell B, Chang C, et al:: GLI1 regulates a novel neuropilin-2/a6/1 integrin based autocrine pathway that contributes to breast cancer initiation. EMBO Mol Med. 2013; 5(4): 488-508.

PubMed Abstract | Publisher Full Text | Free Full Text

Hingorani SR, Wang L, Multani AS, et al:: Trp53R172H and KrasG12D cooperate to promote chromosomal instability and widely metastatic pancreatic ductal adenocarcinoma in mice. Cancer Cell. 2005; 7(5): 469-83.

PubMed Abstract | Publisher Full Text

Hui CC, Angers S: Gli proteins in development and disease. Annu Rev Cell Dev Biol. 2011; 27: 513-537.

PubMed Abstract | Publisher Full Text

Javelaud D, Pierrat MJ, Mauviel A: Crosstalk between TGF- $\beta$ and hedgehog signaling in cancer. FEBS Lett. 2012; 586(14): 2016-2025.

PubMed Abstract | Publisher Full Text

Ji Z, Mei FC, Xie J, et al:: Oncogenic KRAS activates hedgehog signaling pathway in pancreatic cancer cells. J Biol Chem. 2007; 282(19): 14048-14055.

PubMed Abstract | Publisher Full Text

Jones S, Zhang X, Parsons DW, et al.: Core signaling pathways in human

pancreatic cancers revealed by global genomic analyses. Science. 2008 ;

321(5897): 1801-6.

PubMed Abstract | Publisher Full Text | Free Full Text

Joost S, Almada LL, Rohnalter V, et al:: GLI1 inhibition promotes epithelial-tomesenchymal transition in pancreatic cancer cells. Cancer Res. 2012; 72(1): 88-99. PubMed Abstract | Publisher Full Text | Free Full Text

Kinzler KW, Bigner SH, Bigner DD, et al:: Identification of an amplified, highly expressed gene in a human glioma. Science. 1987; 236(4797): 70-73.

PubMed Abstract | Publisher Full Text

Lauth M, Bergstrom A, Shimokawa T, et al.: DYRK1B-dependent autocrine-toparacrine shift of Hedgehog signaling by mutant RAS. Nat Struct Mol Biol. 2010; 17(6): 718-725.

PubMed Abstract | Publisher Full Text

Lee JJ, Perera RM, Wang H, et al.: Stromal response to Hedgehog signaling restrains pancreatic cancer progression. Proc Natl Acad Sci U S A. 2014; 111(30): E3091-3100.

PubMed Abstract | Publisher Full Text | Free Full Text

LoRusso PM, Rudin CM, Reddy JC, et al:: Phase I trial of hedgehog pathway inhibitor vismodegib (GDC-0449) in patients with refractory, locally advanced or metastatic solid tumors. Clin Cancer Res. 2011; 17(8): 2502-2511. PubMed Abstract | Publisher Full Text

Mahadevan D, Von Hoff DD: Tumor-stroma interactions in pancreatic ductal adenocarcinoma. Mol Cancer Ther. 2007; 6(4): 1186-1197.

PubMed Abstract | Publisher Full Text

McMahon AP, Ingham PW, Tabin CJ, et al:: Developmental roles and clinical significance of hedgehog signaling. Curr Top Dev Biol. 2003; 53: 1-114. PubMed Abstract | Publisher Full Text

Mills L, Zhang DL, Marler R, et al.: Inactivation of the transcription factor GLI1 accelerates pancreatic cancer progression. J Biol Chem. 2014; 289(23): 16516-25. PubMed Abstract | Publisher Full Text | Free Full Text

Mills LD, Zhang Y, Marler RJ, et al:: Loss of the transcription factor GLI1 identifies a signaling network in the tumor microenvironment mediating KRAS oncogene-induced transformation. J Biol Chem. 2013; 288(17): 11786-11794. PubMed Abstract | Publisher Full Text | Free Full Text

Nolan-Stevaux O, Lau J, Truitt ML, et al.: GLI1 is regulated through Smoothenedindependent mechanisms in neoplastic pancreatic ducts and mediates PDAC cell survival and transformation. Genes Dev. 2009; 23(1): 24-36.

PubMed Abstract | Publisher Full Text | Free Full Text

Nye MD, Almada LL, Fernandez-Barrena MG, et al.: The transcription factor GLI1 interacts with SMAD proteins to modulate transforming growth factor $\beta$-induced gene expression in a p300/CREB-binding protein-associated factor (PCAF)-dependent manner. J Biol Chem. 2014; 289(22): 15495-506. PubMed Abstract | Publisher Full Text | Free Full Text

Olive KP, Jacobetz MA, Davidson CJ, et al.: Inhibition of Hedgehog signaling enhances delivery of chemotherapy in a mouse model of pancreatic cancer. Science. 2009; 324(5933): 1457-1461.

PubMed Abstract | Publisher Full Text | Free Full Text

Ougolkov AV, Fernandez-Zapico ME, Savoy DN, et al.: Glycogen synthase kinase3beta participates in nuclear factor kappaB-mediated gene transcription and cell survival in pancreatic cancer cells. Cancer Res. 2005; 65(6): 2076-2081. PubMed Abstract | Publisher Full Text

Pan X, Arumugam T, Yamamoto T, et al.: Nuclear factor-kappaB p65/relA silencing induces apoptosis and increases gemcitabine effectiveness in a subset of pancreatic cancer cells. Clin Cancer Res. 2008; 14(24): 8143-8151. PubMed Abstract | Publisher Full Text

Rajurkar M, De Jesus-Monge WE, Driscoll DR, et al.: The activity of Gli transcription factors is essential for Kras-induced pancreatic tumorigenesis. Proc Natl Acad Sci U S A. 2012; 109(17): E1038-1047.

PubMed Abstract | Publisher Full Text | Free Full Text

Rhim AD, Oberstein PE, Thomas DH, et al:: Stromal elements act to restrain, rather than support, pancreatic ductal adenocarcinoma. Cancer Cell. 2014; 25(6): 735-747.

PubMed Abstract | Publisher Full Text | Free Full Text

Seidel B, Braeg S, Adler G, et al.: E- and N-cadherin differ with respect to their associated p120ctn isoforms and their ability to suppress invasive growth in pancreatic cancer cells. Oncogene. 2004; 23(32): 5532-5542.

PubMed Abstract | Publisher Full Text

Thayer SP, di Magliano MP, Heiser PW, et al.: Hedgehog is an early and late mediator of pancreatic cancer tumorigenesis. Nature. 2003; 425(6960): 851-856. PubMed Abstract | Publisher Full Text | Free Full Text

von Burstin J, Eser S, Paul MC, et al: E-cadherin regulates metastasis of pancreatic cancer in vivo and is suppressed by a SNAIL/HDAC1/HDAC2 repressor complex. Gastroenterology. 2009; 137(1): 361-371, 371.e1-5. PubMed Abstract | Publisher Full Text

Wang W, Abbruzzese JL, Evans DB, et al:: The nuclear factor-kappa B RelA transcription factor is constitutively activated in human pancreatic adenocarcinoma cells. Clin Cancer Res. 1999; 5(1): 119-127. PubMed Abstract

Yauch RL, Gould SE, Scales SJ, et al:: A paracrine requirement for hedgehog signalling in cancer. Nature. 2008; 455(7211): 406-410.

PubMed Abstract | Publisher Full Text 


\section{Open Peer Review}

\section{Current Peer Review Status:}

\section{Version 1}

Reviewer Report 23 October 2014

https://doi.org/10.5256/f1000research.5682.r6366

(C) 2014 Stecca B. This is an open access peer review report distributed under the terms of the Creative Commons Attribution License, which permits unrestricted use, distribution, and reproduction in any medium, provided the original work is properly cited.

\section{Barbara Stecca}

Laboratory of Tumor Cell Biology, Core Research Laboratory-Istituto Toscano Tumori, Florence, Italy

This review provides a comprehensive summary about the role of the transcription factor GLI1 in pancreatic cancer (PDAC). This manuscript highlights the dual role of GLI1 during pancreatic carcinogenesis, acting as an oncogene in the early stages of disease and as a tumor-suppressor in the late stages. Recent evidence suggests the loss of GLI1 in the later stages of PDAC might accelerate disease progression. This might explain why Smoothened (SMO) inhibitors have been successful for treating basal cell carcinoma and medulloblastoma, but do not appear to have the same effect in metastatic PDAC. Moreover, this article summarizes recent data on the integration of GLI1 with other signaling pathways, suggesting that GLI1 is not only regulated by the upstream Hedgehog signaling in a SMO-dependent manner, but also by other oncogenic inputs, such as KRAS, TGF-beta and EGFR signaling.

Recent experimental data suggest that lower GLI1 levels associate with PDAC progression, whereas increasing GLI1 levels could drive terminal differentiation and decreased PDAC tumorigenicity. What is missing in this review is a consideration about the factors that might contribute to decrease GLI1 levels and activity during PDAC progression. I would also suggest to mention in the Discussion that the dual role of GLI1 is so far limited to PDAC, as the evidence is lacking in other cancer types.

Competing Interests: No competing interests were disclosed.

I confirm that I have read this submission and believe that I have an appropriate level of expertise to confirm that it is of an acceptable scientific standard. 
Martin Fernandez-Zapico, Mayo Clinic, Rochester, USA

1. Recent experimental data suggest that lower GLI1 levels associate with PDAC progression, whereas increasing GLI1 levels could drive terminal differentiation and decreased PDAC tumorigenicity. What is missing in this review is a consideration about the factors that might contribute to decrease GLI1 levels and activity during PDAC progression.

Response: We added additional considerations regarding other factors that may drive down GLI1 levels during PDAC progression to the "Discussion" section.

Mechanisms included are activation of DYRK1B kinase, which promotes a shift from autocrine to paracrine signaling, which may lead to decreased GLI1 expression. Also, decreased $\mathrm{HH}$ signaling in advanced PDAC may allow for increased expression of GLI1 repressors.

2. I would also suggest to mention in the Discussion that the dual role of GLI1 is so far limited to PDAC, as the evidence is lacking in other cancer types.

Response: The following statement was added to the final paragraph of the Discussion section "Further studies are needed to fully understand the role of GLI1 in PDAC carcinogenesis. While there is evidence for a dual role of GLI1 in PDAC, this phenomenon has yet to be linked with other cancer types."

Competing Interests: None

Reviewer Report 21 October 2014

https://doi.org/10.5256/f1000research.5682.r6367

(C) 2014 Riobo N. This is an open access peer review report distributed under the terms of the Creative Commons Attribution License, which permits unrestricted use, distribution, and reproduction in any medium, provided the original work is properly cited.

\section{Natalia Riobo}

Kimmel Cancer Center, Thomas Jefferson University, Philadelphia, PA, USA

The review is timely and addresses a very important problem in pancreatic cancer. The Smoothened inhibitors that work well for other tumor types have not only failed to stop the progression, but instead promote aggressive behavior in pancreatic cancer. The authors make a good case of balancing the evidence that suggests that there is $\mathrm{HH}$-independent upregulation of GLI1 in the epithelial cells and a Hh-dependent upregulation in fibroblasts. Moreover, they nicely discuss how GLI1 is necessary for PanIN formation and then restrains further cancer progression. What is lacking in the review is a consideration of potential non-canonical effects of the Smo inhibitors. It is known that Smo induces cytoskeletal changes in fibroblasts, for instance, and that it can regulate glucose uptake in other cell types. Perhaps modulation of GLI1 is a bystander effect 
confusing the results. And the GLI1 knockout animals only partly acknowledge this interpretation, since some effects can be cell-type specific and opposing, as discussed in the review.

A minor criticism is the following: the introduction erroneously says that GLI1 is conserved from Drosophila to humans. However, GLI3 is the closest homolog in sequence and function to Drosophila $\mathrm{Ci}$. It seems that the authors meant the GLI family is conserved.

Competing Interests: No competing interests were disclosed.

\section{I confirm that I have read this submission and believe that I have an appropriate level of expertise to confirm that it is of an acceptable scientific standard.}

Author Response ( ) 14 Jun 2016

Martin Fernandez-Zapico, Mayo Clinic, Rochester, USA

1. What is lacking in the review is a consideration of potential non-canonical effects of the Smo inhibitors. It is known that Smo induces cytoskeletal changes in fibroblasts, for instance, and that it can regulate glucose uptake in other cell types. Perhaps modulation of GLI1 is a bystander effect confusing the results. And the GLI1 knockout animals only partly acknowledge this interpretation, since some effects can be cell-type specific and opposing, as discussed in the review.

Response: Additional considerations were added concerning the use of SMO inhibitors and downstream GLI-independent effects to the Discussion section.

2. A minor criticism is the following: the introduction erroneously says that GLI1 is conserved from Drosophila to humans. However, GLI3 is the closest homolog in sequence and function to Drosophila Ci. It seems that the authors meant the GLI family is conserved.

Response: This statement was corrected to "the GLI family of transcription factors is highly conserved and is required for developmental response via transcriptional regulation of target genes" in the Introduction. The statement regarding Drosophila to humans was removed.

Competing Interests: None

Reviewer Report 16 October 2014

https://doi.org/10.5256/f1000research.5682.r6370

(C) 2014 Mauviel A. This is an open access peer review report distributed under the terms of the Creative Commons Attribution License, which permits unrestricted use, distribution, and reproduction in any medium, provided the original work is properly cited. 


\begin{abstract}
Alain Mauviel
Team "TGF- $\beta$ and Oncogenesis", Centre de Recherche, Institut Curie, Orsay, France

In this article Hogenson et al. provide us with a timely review regarding the current knowledge about the role of the transcription factor GLI1 in pancreatic carcinoma. There is an important focus on the dual activity of GLI1 during pancreatic carcinogenesis depending on the stage of disease progression, as evidenced in most recent works in this field, both clinical and experimental, that are nicely summarized in this review.

Another important aspect of this review consists in integrating GLI1 as a transcription factor that is not solely regulated by Hedgehog signaling downstream of SMO but also by other protumorigenic pathways, such as TGF-beta and KRAS signaling.
\end{abstract}

Overall, I believe that this manuscript is very focused and contains valuable information for the broader readership, with up-to-date citation of the most relevant and recent literature in the field.

A couple of minor points may be corrected or improved:

1. A figure summarizing the role of GLI1 downstream of the various pathways described to modulate its expression/activity would be helpful.

2. On page 3, one reads "TGF $\beta$ induces the expression of GLI1 through Smad3 and LETdependent up regulation of GLI2". "LET-dependent" should be replaced by beta-catenin/LEFTCF-dependent or something similar.

Competing Interests: No competing interests were disclosed.

I confirm that I have read this submission and believe that I have an appropriate level of expertise to confirm that it is of an acceptable scientific standard.

Author Response ( ) 14 Jun 2016

Martin Fernandez-Zapico, Mayo Clinic, Rochester, USA

1. A figure summarizing the role of GLI1 downstream of the various pathways described to modulate its expression/activity would be helpful.

Response: An additional figure was added to the review (Figure 1) to describe the various pathways that modulate GLI1 expression as discussed in the review. Figure 1 from the first version of this article was changed to Figure 2.

2. On page 3, one reads "TGF $\beta$ induces the expression of GLI1 through Smad3 and LETdependent up regulation of GLI2". "LET-dependent" should be replaced by betacatenin/LEF-TCF-dependent or something similar.

Response: "LET-dependent" was corrected to " $\beta$-catenin/LEF-TCF-dependent" on page 3. 


\section{Competing Interests: None}

The benefits of publishing with F1000Research:

- Your article is published within days, with no editorial bias

- You can publish traditional articles, null/negative results, case reports, data notes and more

- The peer review process is transparent and collaborative

- Your article is indexed in PubMed after passing peer review

- Dedicated customer support at every stage

For pre-submission enquiries, contact research@f1000.com 